\title{
GENETIC MODIFICATION FOR SALT AND DROUGHT TOLERANCE IN PLANTS THROUGH SODERF3
}

\author{
ALI M, RAFIQUE F, *ALI Q, MALIK A \\ Institute of Molecular Biology and Biotechnology, The University of Lahore, Lahore, Pakistan \\ Corresponding author email: saim1692@gmail.com
}

(Received, $17^{\text {th }}$ May 2020, Revised $21^{\text {th }}$ August 2020, Published $25^{\text {th }}$ August 2020)

\begin{abstract}
Plants constitute the major part of the ecosystem and maintain balance through their different roles in the stability of the environment. As plants have an impact over environment; in the same manner environment interacts with plants. These interactions bring some productive results or sometimes may cause serious issues to plants. The environment poses some serious threats to plants as it is changing drastically over the course of years. Plants have been resistant to many of biotic and abiotic stresses naturally but now it is getting challenging. The major issues faced by plants are drought, high salt concentration, temperature and many other factors. These issues can be compensated by engineering plants with such novel genes which cause the release of ethylene responsive factor in the case of drought and salt intolerance. There are various studies to engineer the stress sensitive plants with SodERF3, a novel sugarcane ethylene responsive factor which causes promising tolerance in transgenic plants.
\end{abstract}

Keywords: salt, drought, SodERF3, sugarcane, genetic engineering, transgenic plants

\section{Introduction}

There are countless problems which are presented to plants, as if instance is taken, high salt concentration, low temperature, flooding, dry spell, oxidative pressure, heat, and considerable metal poisonousness which ultimately impose stress to plants. Abiotic stress recurrently prompts impediment in plant development. It has been evaluated that abiotic stresses were the chief reason for diminishing the normal yield of significant harvests by over half. To stand up to such natural hostilities, plants have shown great potential of versatile reactions at physiological and sub-atomic levels, which are triggered under such pressure conditions (Dong et al., 2004). Plants exhibit various safeguard systems that have the capacity to maximize the resistance to the unfavorable conditions caused by abiotic stresses. A significant occasion noticed because of stress is the observation and transduction of stress signals through flagging segments, which brings about the initiation of various qualities that prove to be very effective in stress conditions. The ability of possessing these qualities lead to the release of plant hormones like ethylene and abscisic acid etc. (Quan et al., 2014). These hormones have the ability to start a cycle of declining the stress that is being faced by them that ultimately contribute to the overall reaction of plants towards stress. Ethylene end up being associated with plant pressure reactions as a plant hormone which is vaporous, in spite of its jobs in natural product maturing, germination, microbe reaction, senescence, organ abscission, etc. A few reports proposed that accretion of ethylene or its forerunner, the ACC (aminocyclopropane-1-carboxylic corrosive) is incredibly prompted by abiotic stress boosts, for example, water pressure, saltiness, and flooding (Borrás-Hidalgo et al., 2004).

Plants devote a large portion of their genome to genes that are involved in transcription, as it can be illustrated by the Arabidopsis thaliana genome that encodes about 1,500 transcription factors (TFs). Most of these TFs are grouped in large families, some of which are unique to plants (Riechmann et al. 2000). One group of plant-specific transcription factors encompasses the so-called ethylene-responsive factors (ERFs) that act at the last step of ethylene signaling pathways, the first member of which was identified in tobacco. To date, in different plant species ERFs have been found to be involved in growth, development and regulation of metabolism, but also in the response to biotic and abiotic stress. ERF proteins contain a very characteristic and highly conserved plant-specific DNA-binding domain that consists mainly of 58-59 amino acids structured as a three-stranded antiparallel b-sheet and an a-helix in parallel to the b-sheet. Two similar cis-elements have been identified as binding sites in the promoters of ERF controlled genes: the GCC box that is typically identified in pathogenesis-related (PR) genes, and the

[Citation: Ali, M., Rafique, F., Ali, Q., Malik, A. (2020). Genetic modification for salt and drought tolerance in plants through SODERF3. Biol. Clin. Sci. Res. J., 2020: 22 doi: https://doi.org/10.54112/bcsrj.v2020i1.22]. 
C-repeat (CRT)/dehydration-responsive element (DRE) motif in dehydration- and low-temperatureresponsive genes. ERFs belong to the large APETALA2 (AP2)/ERF TF super family that is unique to plants. The AP2 domain group comprises 4150 ERF genes classified into two subgroups A and $\mathrm{B}$, each of which is further divided into six clusters based on sequence conservation.

Preliminary analysis of the A and B subgroups based on data from overexpression experiments and transcriptional activation suggests that TFs belonging to subgroup A are involved in abiotic stress responses, while those ones involved in disease resistance responses are found in the B subgroup. Sugarcane (Saccharum officinarum L.) is a tropical grass that has been cultivated for 44,000 years. In recent years, sugarcane cultivation occurs worldwide in tropical and subtropical regions and contributes $460 \%$ of the world sugar production. Importantly, sugarcane biomass is also increasingly used for the production of bioethanol as an alternative to petroleum-derived fuels. Despite its economic importance, sugarcane genetics is still in its infancy, which is largely due to the poor availability of genetics tools for Saccharum species. This may be explained by the complexity of the sugarcane genome, which exceeds that of any other crop plant. Although a large amount of DNA sequence information for sugarcane was released into the public domain as expressed sequence tags (ESTs) derived from cDNA libraries, few genes that govern biotic or abiotic stress responses have been molecularly characterized from this crop to date. It is well known that phytohormones mediate development and stress response by modulating the expression of specific subsets of hormone-responsive genes. Ethylene, for example, affects the expression of a group of genes related to pathogen attack, wounding, abnormal temperatures and drought stress Our search for sugarcane genes involved in ethylene responses led to the identification of a new sugarcane member of the ERF transcription factor family, named SodERF3, with the predicted characteristic DNA-binding domain, a nuclear localization signal (NLS) and a C-terminal ERF-associated amphiphilic repression (EAR)-like motif. A detailed phylogenetic analysis with other members of the AP2/ERF TFs indicates that SodERF3 belongs to subgroup VIII together with class II ERFs containing an EAR motif. Constitutive expression of the SodERF3 gene in tobacco did not lead to phenotypical changes in plant growth and development, but enhanced drought and salt tolerance, a desired trait for crop engineering.

SodERF3, a sugarcane (Saccharum officinarum L. cv Ja60-5) cDNA that encodes a 201-amino acid DNA- binding protein that acts as a transcriptional regulator of the ethylene responsive factor (ERF) superfamily. Like other ERF transcription factors, the SodERF3 protein binds to the GCC box, and its deduced amino acid sequence contains an N-terminal putative nuclear localization signal (NLS). In addition, a Cterminal short hydrophobic region that is highly homologous to an ERF-associated amphiphilic repression-like motif, typical for class II ERFs, was found. Northern and Western blot analysis showed that SodERF3 is induced by ethylene. In addition, SodERF3 is induced by ABA, salt stress and wounding. Greenhouse-grown transgenic tobacco plants (Nicotiana tabacum L. cv. SR1) expressing SodERF3 were found to display increased tolerance to drought and osmotic stress.

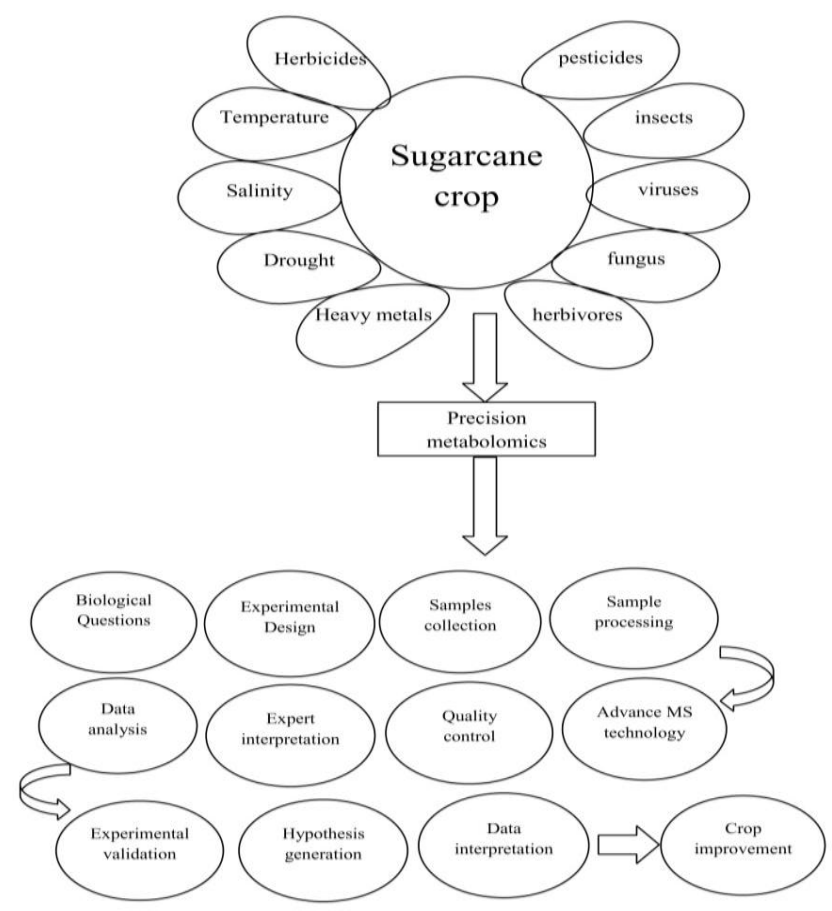

Figure 1: A general pathway showing the improvement in the tolerance of sugarcane plants. Plants Growth and role of different hormones

Plant growth regulating hormones play vital role in meristmetic activities of roots (Orlowska et al., 2012).It has been reported that antagonistic activity of auxin and cytokinin helps in maintainance of root growth through cell division (Anderson et al., 2010). During active divisions of cells in roots cytokinin stimulate ARRI which triger the sypocotoyl by suppressing the auxin signals (Kloepper et al., 2004). It has been cited that Cytokinin oxidase4 helps in root growth by mixing ratio of both auxin and cytokinin. (Mith, 2008).Earlier it was considered that rice variety WOX11 was involved in growth of crown root (part of a root system from which a stem arises).

[Citation: Ali, M., Rafique, F., Ali, Q., Malik, A. (2020). Genetic modification for salt and drought tolerance in plants through SODERF3. Biol. Clin. Sci. Res. J., 2020: 22 doi: https://doi.org/10.54112/bcsrj.v2020i1.22]. 
The proliferation of crown root requires the presence of WOX11 transcriptional factor by bringing change in genes of signaling hormones (Jackson et al., 2012). ERF protein was identified in rice which was in interaction with WOX11 in crown roots. Results revealed that ERF3 and excessive quantity of RR2 (response regulator 2) were in direct contact with crown root growth. From this research it might be proposed that ERF3 might deal with cytokinin but its collaboration with WOX11 can affect crown root by increasing or suppressing the function of signaling molecules. This technique can induce resistance in infectious pathogens through ISR (integrated stress response). In this way plants increase their defensive mechanism (which might include merging of cell wall, various enzymes etc) against various pathogens (Alkalaeva et al., 2006). Activation of ISR proved to be useful in fighting with pathogens, irrespective of decline in population of bacteria. Crop yield of potato can also be enhanced by trigging the establishment of MIR (mycorrhizal-induced resistance) with AMF (Arbuscular mycorrhizal fungi) (Salas et al., 2004). Most of the higher plants and symbiotic association of AMF have basic farming crops i.e potato. In their association they obtain carbohydrates from plants and in return give them phosphorus and water. In plants SA(Salicylic acid), JA (Jasmonic acid) and ethylene are directly involved in inducing resistance mechanism. Jasmonic acid and ethylene induction helps in ISR regulation (integrated stress response) which eventually leads towards defense in plants. SAR (systemic acquired resistance) is also found in plants and stimulated against infectious agents which promote easily offending response in leaves of plants (Shoemaker et al., 2004). Tissues at infectious site have shown long term resistance towards disease causing agents.At initial stage PR1 protein (Pathogenesis-related) and these are used against pathogens is used in order to express those genes which were induced earlier through salicylic acid which is an important plant hormone that regulates many aspects of plant growth and development, as well as resistance to abiotic stress and pathogenic attacks. Those phytohormones which are being used in defense mechanism are basically identified through the nature of infectious agents.In various circumstances it has been observed that ISR stimulate those pathways which were dependent on salicylic acid. When resistance inducers work in collaboration they showed improved regulatory mechanism in plants (Eurwilaichitr et al., 1999). Successful attempts were made to increase the efficiency of ISR by combining of defense bioprimers with various bacterial strains (Cheng et al., 2009). In order to boost up RMISR (root-microbe interactions regulators) and yield in plants various strategies including bacterial combination with AMF etc were utilized. Whereas, bacterial associations with plants at molecular level remained indefinable and is still under consideration for certain diseases in crops (Merkulova et al., 1999).

\section{Crop Yield Increase}

One of the major challenges being faced now a days is to fulfill the nutritional demand of population. In order to obtain desirable outcome of crops various enzymes are being used. For this purpose RubisCO enzyme is taken under consideration for converting carbondioxode into useful organic compounds (des Georges et al., 2014). Carbondioxide, water and 2 molecules of 3-PG from RuBP were generated because of carboxylase activity of RubisCO. The oxidation reaction reduces the ability of carbon fixation. Few plants suppress the oxygenase activity with the help of their system in order to enhance the level of carbon dioxide where RubisCO can act on C4 plants which are plants that cycles carbon dioxide into four-carbon sugar compounds to enter into the Calvin cycle which include sugarcane etc. (Taylor et $a l ., 2012)$. As we all are familiar that $\mathrm{C} 3$ plants have greater level of photorespiration and spend greater energy on it which ultimately lead towards slow growth.So, RubisCO engineering with the enhanced kinship of carbondioxide might be important for overall outcomes of crops (Gross et al., 2007).

\section{Transcription factors and their role in plants}

Transcription factors are considered to play significant role at transcription level. They either suppress or activate the genes under various diverse conditions. Transcription factors account for nearly $7 \%$ coding capacity of vascular plant genome as they regulate genes at the level of transcription. In plants, thousands of transcription factors have been identified. From the major families of TFs one is AP2/ERF and are mediated by various different signaling transduction pathways. They are being utilized for coping up both the biotic and abiotic stress. Still a lot of research needs to be done for identifying the applications of transcription factor genes, these genes are helpful to produce stress resistant crops having high productivity, so that the food security can be ensured (Alcazar-Roman et al., 2010). There are some advance gene editing tools like CRISPR/Cas9 and these tools can be explored in the near future. Due to the complex polypoid genome of Saccharum, several transcription factors like MYB, NAC and AP2/ERF transcription factors have not been identified yet. Today, there is dire need to employ molecular breeding tools for improving the sugarcane yield for farmers having crops with small genetic variances. Moreover, epigenetics is 
considered for better understanding the natural procedures during environment stresses. This technique involves DNA methylation, histone alteration, chromatin remodeling and non-coding RNA (Bolger et al., 2008).

\section{Issue of salinity in plants}

Salinity is considered as chief abiotic stress that limits growth as well as productivity of plants in several areas around the world. It is increasing because of elevated usage of poor quality water for both soil salinization and irrigation. Various complex physiological traits, molecular or genetic networks and metabolic pathways are involved for development of tolerance in plants against salinity stress. Development of salt tolerance in salt affected areas involve several molecular tools along with physiological and biochemical techniques. All these techniques are imperative for developing tolerance. Adaptive responses have been identified for salinity stress at different levels i-e metabolic, cellular, molecular and physiological (Bolger et al., 2008).

Changes in physiological and metabolic processes are involved under salinity stress. This depends upon both the duration and severity of the stress, which in turns inhibit crop production. Primarily soil salinity represses the growth of plant in the osmotic stress form, which is later followed by ion toxicity (Khoshnevis et al., 2010). During the early phases of stress, capacity of roots to absorb water declines and water loss from the leaves increases because of osmotic stress of high salt accumulation in the soil and plants. Thus, salinity stress is also considered as hyperosmotic stress as well as hyperionic stress (Mikhailovaet al., 2017). Osmotic stress in the early stages of salinity stress is involved in causing several physiological changes like nutrient imbalance, membrane interruption, lowered photosynthetic activity, difference in antioxidant enzymes and et al., 2016).

\section{Gene Transformation Technologies}

Quality exchange can be accomplished in unsurprising way by hereditary change innovation. In this manner, these strategies would be valuable in controlling the pathways related to osmoprotectants biosynthesis to collect those particles that can demonstration by searching ROS protein (Kispal et al., 2005). Numerous investigations directed in the past draw attention to the plant alteration system that assists with improving saltiness resistance, and furthermore center around the qualities that control particle transport since sodium take-up's guideline is altogether significant for endurance of plants under saltiness stress. Numerous qualities that control this component have additionally been distinguished. It has been seen that building plants for over-expressing reduction in stomatal aperture (Beznoskova et al., 2013). Accumulation of sodium and chloride ions in plant tissues are ultimately released in soil. Soil with high sodium chloride concentration is considered as one of the most damaging effects of salinity stress. Entrance of both sodium and chloride ion in the cells leads to severe ionic imbalance and the excess uptake can also cause major physiological disorder. Uptake of potassium ion is inhibited by high concentration of sodium ion. Potassium is essential for both growth and development that later results in decreased productivity and can lead to death (Tieg et al., 2013). As a result of salinity stress, ROS production like singlet oxygen, hydroxyl radical, and hydrogen peroxide is increased. This can result in oxidative damages in several cellular components like lipids, proteins and DNA which later affects the chief cellular functions of the plants (Noble et al., 2011).

\section{Genetic variations and tolerance in plants:}

Genetic variations in salt tolerance have been noticed, and the extent of salt tolerance changes with species of plants as well as varieties within a specie. Among key crops, a greater degree of salt tolerance has been shown by barley as compared to wheat and rice. This degree of variation is even more noticed in dicotyledons cases that range from Arabidopsis thaliana which is extremely sensitive to salinity, to halophytes like Atriplex sp., Mesembryanthemum crystallinum and Thellungiella salsuginea. In order to understand the mechanism of salt tolerance in Arabidopsis, excessive research has been done in the past two decades. Now biologists can study or identify the physiological mechanisms, gene products and sets of genes by genetic variations as well as differential responses to salinity stress in plants. These sets of genes are involved in elevating stress tolerance and incorporating them in suitable species so that they can yield salt tolerant varieties (Neumann

qualities that encode antiporters are recognized as viable technique to produce salt resistant plants (Strunk et al., 2012). Quality expression focuses on those promoters which are constitutive. These convey just restricted genetic data. When these were contrasted with the use of inducible expression factors or cell type open expression factors, it may be said that the determination of expression factors can enormously influence the outcomes from transgenic control. Subsequently, building of salt lenient yields should be possible by fruitful adjusting of pressure reaction through designing of novel administrative targets total comprehension of post-translational changes which are useful in managing the development of plants under pressure conditions. There is support of hormone homeostasis in plants 
for keeping away from pleiotropic impacts under pressure; and by use of plants some specific techniques for improving methodologies of hereditary structure transfers are applied (Preis et al., 2014). Responses at molecular, cellular, metabolic and physiological level have been observed in salinity tolerance. Extensive research on these responses has depicted several responses or strategies for controlling osmotic regulation, ion uptake, hormone metabolism, and stress signaling play significant role in adapting salinity stress in plants. Now, scientists are advancing in the field of proteomics, transcriptomics, genomics and metabolomics techniques, and they are now able to focus on the development of complete gene and protein profiles, and metabolites that are responsible for dissimilar method of salinity tolerance in different species of plants (Barthelme \& Pisarev, 2012).
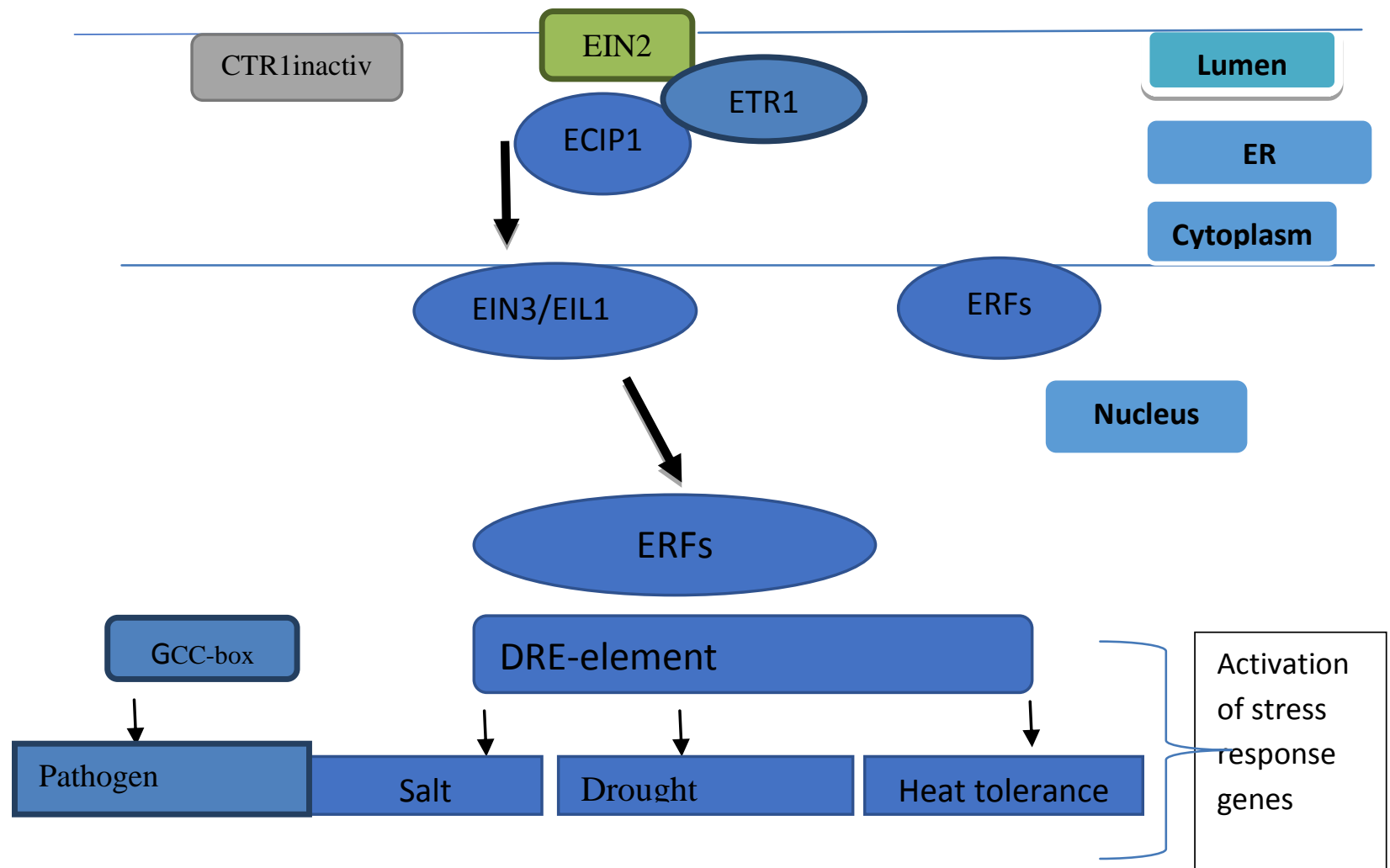

Figure 2: Shows ERF genes playing key role in hormonal regulation against the condition of stress for plants

\section{Regulation factors}

It has been studied that a large portion of plant genome is devoted to their genes that play role in transcription. The same mechanism has also been observed in Arabidopsis thaliana genome which encodes approximately 1500 transcription factors. Majority of the transcription factors are usually grouped in large family, whereas some of these are unique to plants. Out of all, one group of TFs covers so called ethylene responsive factors that usually act upon the end step of ethylene signaling pathways. Its first member was identified in tobacco (Anderson et al., 2004). Till today, ethylene responsive factors in various plant species have been identified to have role in growth, development as well as metabolism regulation. The agricultural production worldwide highly depends on the plant's ability to tolerate salt as well as drought conditions. The elevated understanding regarding regulatory networks that control drought stress response has led to practical methods in order to engineer drought and salt tolerance in the plants (Casu et al., 2004). A supposed protein having a DNA binding domain generally present in EREBP/ AP2-type TFs was found by an expressing sequence tag. From the excised library, a full length cDNA clone i-e SodERF3 was isolated. It has been found that SodERF3 codes DNA binding protein for 240 amino acid (Cavalcante et al., 2007). However, it was also originated that it possesses ERF linked amphiphilic suppression like motif which is not real one. It is a short C-terminal hydrophobic region. The protein binds to GGC box, where SodERF3 binds, and its deduced amino acid sequence contains an N-terminal putative nuclear localization signal and $\mathrm{N}$ terminal putative nuclear localization signal was observed in the deduced amino acid sequence of the protein. In sugarcane leaves, SodERF3 is induced by the

[Citation: Ali, M., Rafique, F., Ali, Q., Malik, A. (2020). Genetic modification for salt and drought tolerance in plants through SODERF3. Biol. Clin. Sci. Res. J., 2020: 22 doi: https://doi.org/10.54112/bcsrj.v2020i1.22]. 
ethylene, salt stress, abscisic acid and wounding as judged by western and northern blot assays. These were grown in greenhouse (Nicotiana tabacum L. cv. SR) that expressed SodERf3 were observed to show elevated tolerance to osmotic stress and drought, and no visible phenotypic change in growth and development was observed in them. Results showed that SodERF3 will act as valuable tool in assisting the manipulation of plants thus they can improve their tolerance of stress (Grivet et al., 2002).

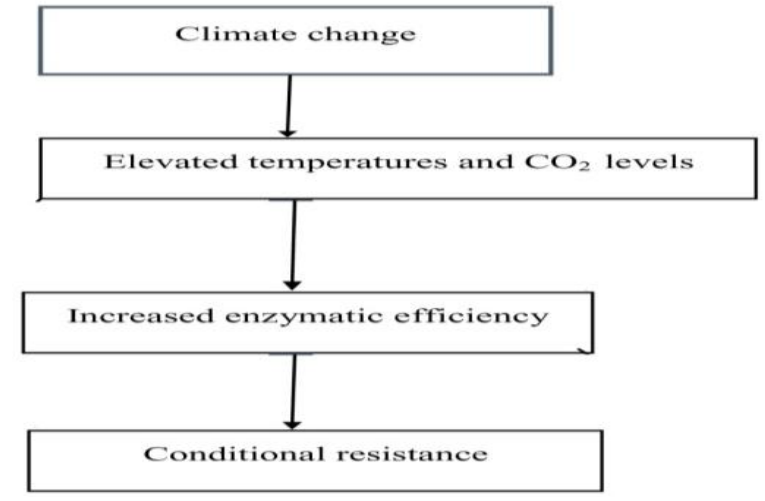

Figure 3: Increasing changes in the climate and weather patterns are making it urgent To increase the tolerance in plant using the technique of SodERF3

Several developments have been made in the recent understanding of gene expression, signal transduction and transcriptional regulation in plants regarding their salinity and drought tolerance. Moreover, gene discovery has been facilitated by molecular as well as genomic analysis. Both of these have enabled the genetic engineering (a field of gene discovery) in activating or repressing specific or broad pathways to drought and salinity tolerance in the plants by utilizing various regulatory or functional genes (Liu et al., 1998). Transcription factors that are concerned in ethylene responsive factors confer tolerance to various abiotic as well as biotic stresses. These Tfs upon activation by ethylene biosynthesis pathway either elevate or decrease the genes' activation regarding stress and vegetative development (Cheng et al., 2013)

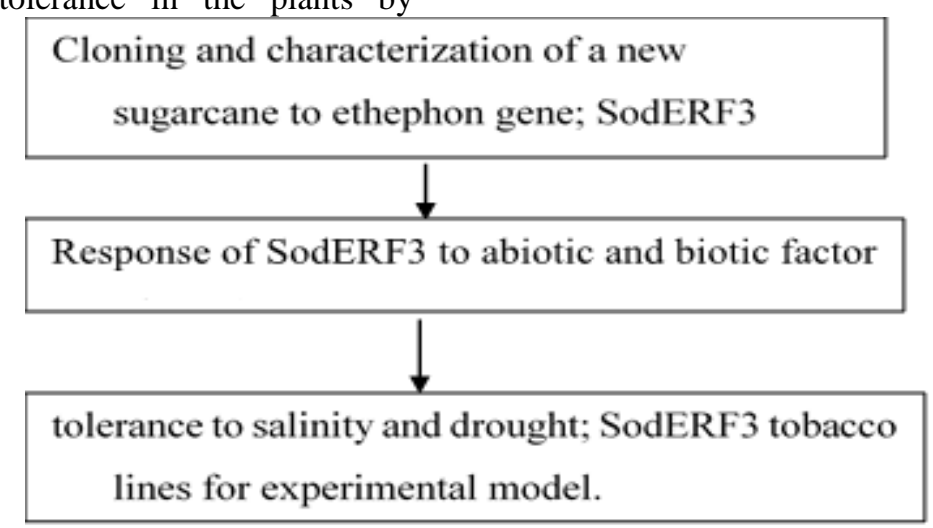

\section{Strategy used in the working}

1. isolate ERF-TF encoding gene from ethephon-treated young leaves of sugarcane

2 . this gene was generated from a $\lambda$ ZAPcDNA library

3. Analysis after cloning of DNA sequence having SodERF3

4. EMBL Gene Bank; new DNA sequence introduction after SodERF3 phylogeny location
5. DNA in vitro binding capacity of protein

6. Gene regulation in plants of sugarcane after treatment with hormones linking abiotic factors

7. In transgenic model plants; biological function will be declared

[Citation: Ali, M., Rafique, F., Ali, Q., Malik, A. (2020). Genetic modification for salt and drought tolerance in plants through SODERF3. Biol. Clin. Sci. Res. J., 2020: 22 doi: https://doi.org/10.54112/bcsrj.v2020i1.22]. 


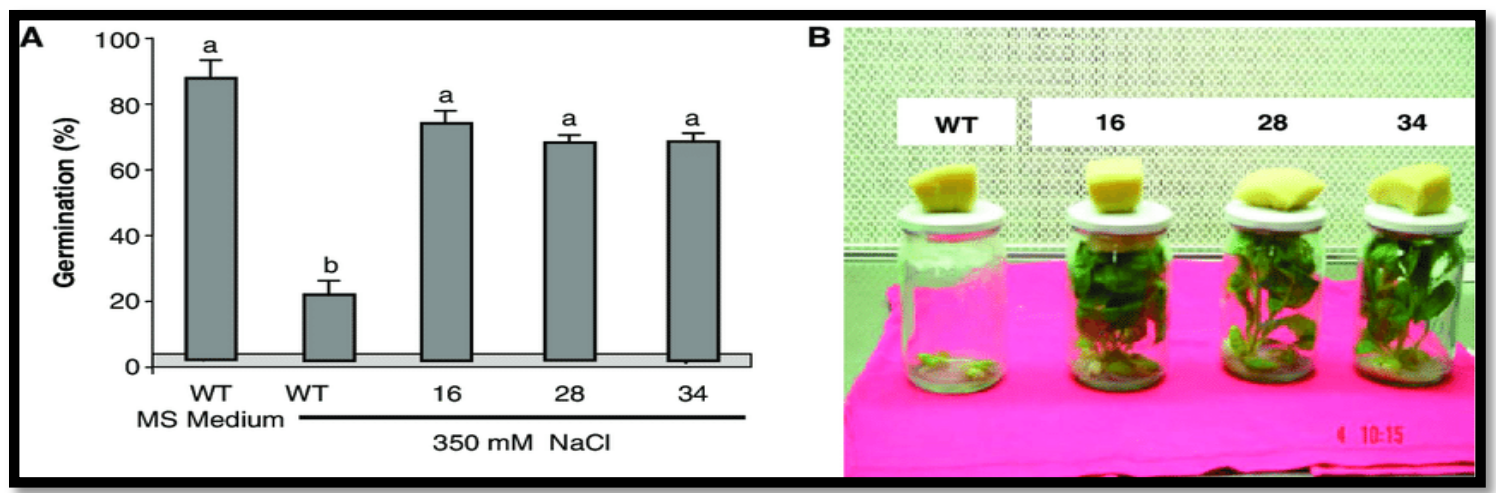

\section{Stress Factors}

Figure 4: Tobacco plant showing SodERF3 expression to exhibit tolerance towards drought and salt after the process of transgenesis (Trujillo et al., 2008)

There are different stress mechanisms which are being shown at different levels in plants under stress response conditions. Transcription factors are considered as important regulators to control the gene expression in every living organism and therefore take part in significant growth of plants, cycling in cell and sign for stress reaction (American association, 1986). Transcription factors are thought to modulate the expression of genes by binding to the local and distal factors which are used as marking genes and later play role in influencing the genomic features, structure of DNA and transcription factor interactions. Inplant, approximately $10 \%$ of genes at various stages encode the transcription factors, thus they can regulate specific signaling mediated functions. There are different main families of transcription factors like NAC, MYB, ERF and WRKY which are used as important regulators for management of stress (Zuo et al., 2007). These later contribute in ideal choice for genetic engineering for elevating resistance of plants against various stress stimuli (Kasuga et al., 2004). It is important to note that till today 44 NAC, 73 AP2/ERF, 38 MYB and 39 WRKY gene families of Transcription factors have been identified in sugarcane (Murashige et al., 1962). In sugarcane, SodERf3 expression is induced by hormones that are involved in both biotic and abiotic stresses. The presence of SodERF3 transcripts in higher quantities are easily detectable in leaves of the sugarcane. It was experimented with a help of stimulus which is quite weak in the presence of treatment of salicylic acid. It was observed that the expression of SodERF3 can be observed by timeline of different experiments as it was shown with ethephon. After ethephon treatment in the span of 1 hour, expression of SodERF3 were noticed in higher quantities (D'Hont et al., 2001). The synthesis of protein and its accumulation also occured gradually after sugarcane leaf disc was treated with ethephon as monitored through western blot. The ethylene responsive part of sugarcane which is being activated by ethephon treatment plays major role in abiotic as well as biotic signaling pathways (Banno et al., 2001) Classification \& Diversification of AP2/ERF Gene Family

Alanine at position 9 and aspartate at position 14 directs the cis element's binding. AP2/ERF is categorized in 5 major groups on the basis of number of domain numbers present in genes. These groups include: DREB (Dehydration responsive element binding protein) AP2, RAV (Related to AB13/VP1), ERF (Ethylene responsive factors). To date, various AP2/ERF transcription factors were identified in many species of plants such as 6 in number factors of AP2/ERF transcription factors in sugarcane (Benson et al., 2002).

\section{Expression of Abiotic Stresses}

It was observed that the identified AP2/ERF transcription factors that are mostly involved in abiotic tolerance belong to Arabidopsis. Increase in tolerance against heat, salt and drought stress in Arabidopsis was displayed by overexpression of sugarcane SodERF3 gene (Gu et al., 2002). It was observed by another study that BnaERF-B3-hy15mu3 mutant gene when over-expressed increases cold resistance in transgenic Arabidopsis which is considered as the model organism against which characteristics of resistance in sugarcane are defined. The action genes if get mutated at the point where GCC box elements are involved then resistance get compromised in sugarcane. From Brassica napus, two groups i.e., DREB I and II regulated the signaling pathway being mediated by DRE synergistically by Trans inactive and active in viable mode (Denekamp et al., 2003). There is an increase in measurement of antioxidants levels, on the other hand lower MDA malondialdehyde values are also observed because of up regulation of the two cold responsive genes in sugarcane. These two cold responsive genes are VaERF080 and VaERF087 in Arabidopsis. It is observed that overexpression of 
BpERF13 in sugarcane led to elevated antioxidants, decreased ROS (reactive oxygen species) and improved tolerance against cold. But it has not shown crucial elevation in salt or drought tolerance .In many plant species, the AP2/ERF transcription factors, have been both identified and characterized for waterlogging (He et al., 2001) . The sugarcane ariel roots that are growing in the stress caused by waterlogging help to maintain the advanced root growth and also a better concentration of ethylene. This concentration contributes in increasing formation of aerenchym (Dey et al., 2015).

Populuseuphratica's expression analysis showed that upregulated expression of PeDREBa depicted much increased values for physio-morphological traits. It also showed high values for signal responsive regulation of both salt stress and drought . Another gene in soyabeani-e GmDREB1 was involved in activating the expression of various soyabean specific stress responsive gene. When transcriptomic analysis was done, it was foundthat AP2si6 was more expressed in transgenic Sesamumindicum, so that it can cope up with deficiency of water. When AtDREB2A CA and OsDREPI were overexpressed, they were found to be conferred to drought endurance in sugarcane and rice respectively. TaDREBI gene was induced through DRE-binding protein, thus it was helpful to improve the sugarcane plant's tendency for tolerating the osmotic variations. Two DREB/CBF genes in sugarcane i-e TaDREB3 and $T a C B F 5 L$ depicted elevated tolerance. This happened under presence of strain receptive promoters $H D Z I-4$ and HDZI-3. The presence of ABA gene, wounding and salt stress in sugarcane induced the SodERF3's expression (Guo et al., 2009).

\section{ERF and stresses from environment}

AP2/ERF transcription factors were involved in regulating disease resistance in plants. Studies showed that when TaPIE1, Soly106, OsEREBP1, OsREF83, and GmERF113 genes were overexpressed, they proved to be effective against the pathogenic infections. Dual regulatory functions of HvRAF (novel AP2/ERF transcription factor) were observed under biotic as well as abiotic stress. Overexpression of TaPIEPI in wheat was majorly induced in Bipolarissorokiniana infection. When TaPIEPI was overexpressed in transgenic plants, it showed much higher resistance against fungal pathogenic infections. Various AP2/ERF3 transcription factors were expressed differently in both susceptible and resistant tomato cultivars concerning TYLCV (Hanna-Rose et al., 1996). Another AP2/ERF3 transcription factor i-e CaERF5 participate in a significant role to protect transgenic tobacco plants. There are expression which are
Ectopic of apple MdERF11 in rejoinder to Botryosphaeriadothidea was observed and it played significant role in higher resistance in Arabidopsis. Thus, it can be said that AP2/ERF transcription factors collectively play significant role in enduring biotic and abiotic stress by various stress mediated signal transduction pathways (Gutterson et al., 2004).

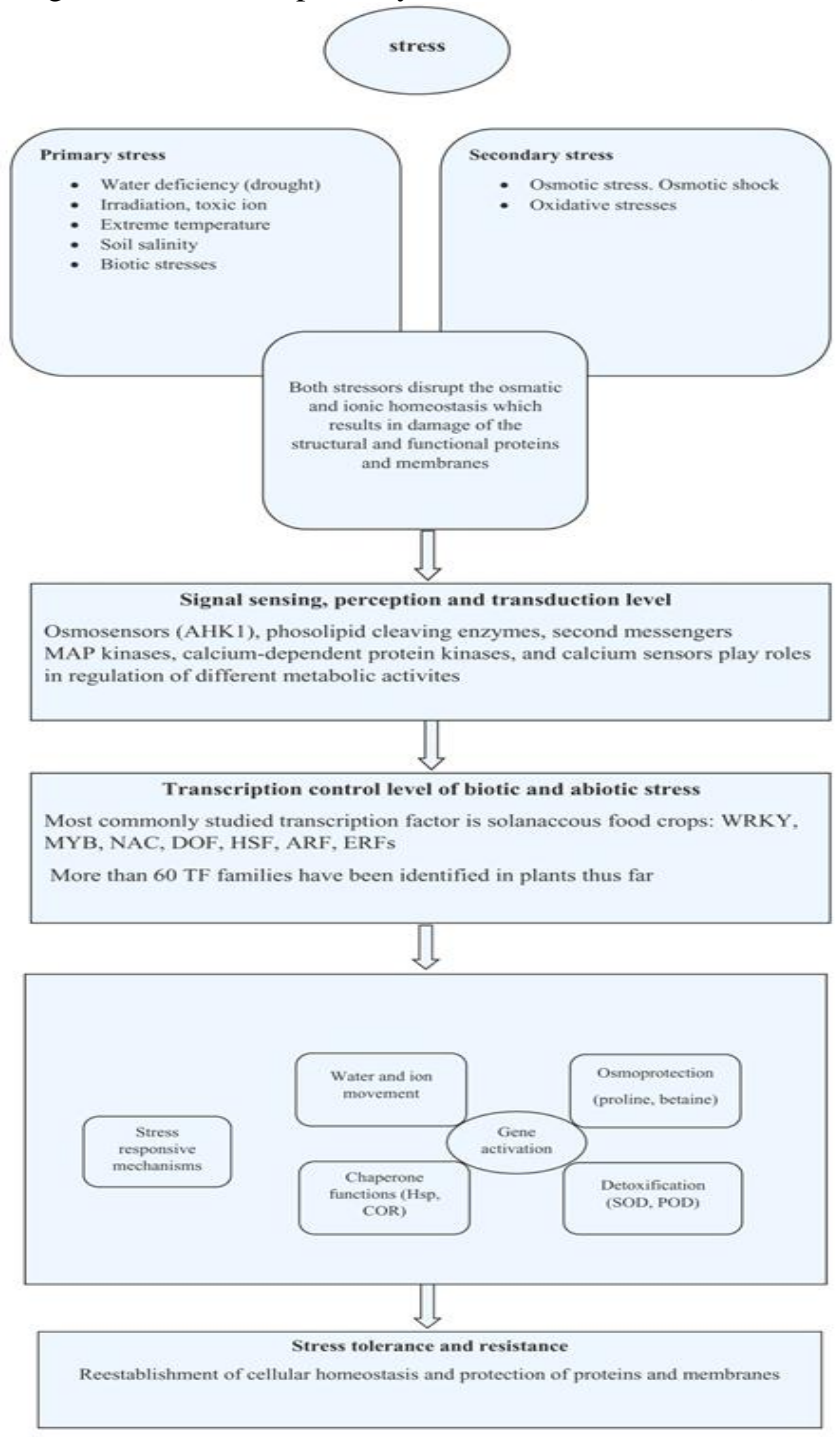

Figure 6: ERF's role in stress tolerance Conflict of interest

The authors declare absence of any conflict of interest.

\section{References}

Alcazar-Roman, A.R., Bolger, T.A. and Wente, S.R. (2010) Control of mRNA export and translation termination by inositol hexakisphosphate requires specific interaction with Gle1. J. Biol. Chem., 285, 16683-16692.

[Citation: Ali, M., Rafique, F., Ali, Q., Malik, A. (2020). Genetic modification for salt and drought tolerance in plants through SODERF3. Biol. Clin. Sci. Res. J., 2020: 22 doi: https://doi.org/10.54112/bcsrj.v2020i1.22]. 
Alkalaeva, E.Z., Pisarev, A.V., Frolova, L.Y., Kisselev, L.L. and Pestova, T.V. (2006) In vitro reconstitution of eukaryotic translation reveals cooperativity between release factors eRF1 and eRF3. Cell, 125, 1125-1136.

Allen, M. D., Yamasaki, K., Ohme-Takagi, M., Tateno, M., \& Suzuki, M. (1998). A novel mode of DNA recognition by a $\beta$-sheet revealed by the solution structure of the GCC-box binding domain in complex with DNA. The EMBO Journal, 17(18), 5484-5496.

American Association for the Advancement of Science. (1985). A simple and general method for transferring genes into plants. Science, 227(4691), 1229-1231.

Anderson JP, Lichtenzveig J, Gleason C, Oliver RP, Singh KB. (2010) The B-3 ethylene response factor MtERF1-1 mediates resistance to a subset of root pathogens in Medicago truncatula without adversely affecting symbiosis adversely affecting
with rhizobia. Plant Physiol., 154:861-73

Anderson, J. P., Badruzsaufari, E., Schenk, P. M., Manners, J. M., Desmond, O. J., Ehlert, C., \& Kazan, K. (2004). Antagonistic interaction between abscisic acid and jasmonate-ethylene signaling pathways modulates defense gene expression and disease resistance in Arabidopsis. The Plant Cell, 16(12), 34603479.

Baierlein, C., Hackmann, A., Gross, T., Henker, L., Hinz, F. and Krebber, H. (2013) Monosome formation during translation initiation requires the serine/arginine-rich protein Npl3. Mol. Cell. Biol., 33, 4811-4823.

Banno, H., Ikeda, Y., Niu, Q. W., \& Chua, N. H. (2001). Overexpression of Arabidopsis ESR1 induces initiation of shoot regeneration. The Plant Cell, 13(12), 2609-2618.

Barthelme, D., Dinkelaker, S., Albers, S.V., Londei, P., Ermler, U. and Tampe, R. (2011) Ribosome recycling depends on a mechanistic link between the FeS cluster domain and a conformational switch of the twin-ATPase ABCE1. Proc. Natl. Acad. Sci. USA, 108, 3228-3233.

Benson, D. A., Karsch-Mizrachi, I., Lipman, D. J., Ostell, J., Rapp, B. A., \& Wheeler, D. L. (2002). GenBank. Nucleic acids research, 30(1), 17-20.

Berrocal-Lobo, M., Molina, A., \& Solano, R. (2002). Constitutive expression of Ethylene-Response-Factor1 in Arabidopsis confers resistance to several necrotrophic fungi. The Plant Journal, 29(1), 23-32.
Beznoskova,P., Cuchalova,L., Wagner,S., Shoemaker,C.J., Gunisova,S., von der Haar,T. and Valasek,L.S. (2013) Translation initiation factors eIF3 and HCR1 control translation termination and stop codon read-through in yeast cells. PLoS Genet., 9, e1003962.

Bolger, T.A., Folkmann, A.W., Tran, E.J. and Wente, S.R. (2008) The mRNA export factor Gle1 and inositol hexakisphosphate regulate distinct stages of translation. Cell, 134, 624-633.

Borrás-Hidalgo, O., Thomma, B. P., Carmona, E., Borroto, C. J., Pujol, M., Arencibia, A., \& Lopez, J. (2005). Identification of sugarcane genes induced in disease-resistant somaclones upon inoculation with Ustilagoscitaminea or Bipolarissacchari. Plant Physiology and Biochemistry, 43(12), 1115-1121.

Broun, P. (2004). Transcription factors as tools for metabolic engineering in plants. Current opinion in plant biology, 7(2), 202-209.

Casu, R. E., Dimmock, C. M., Chapman, S. C., Grof, C. P., McIntyre, C. L., Bonnett, G. D., \& Manners, J. M. (2004). Identification of differentially expressed transcripts from maturing stem of sugarcane by in silico analysis of stem expressed sequence tags and gene expression profiling. Plant molecular biology, 54(4), 503-517.

Cavalcante, J. J. V., Vargas, C., Nogueira, E. M., Vinagre, F., Schwarcz, K., Baldani, J. I., ...\&Hemerly, A. S. (2007). Members of the ethylene signalling pathway are regulated in sugarcane during the association with nitrogenfixing endophytic bacteria. Journal of Experimental Botany, 58(3), 673-686.

Cheng, M. C., Liao, P. M., Kuo, W. W., \& Lin, T. P. (2013). The Arabidopsis ETHYLENE RESPONSE FACTOR1 regulates abiotic stressresponsive gene expression by binding to different cis-acting elements in response to different stress signals. Plant physiology, 162(3), 1566-1582.

Cheng, Z., Saito, K., Pisarev, A.V., Wada, M., Pisareva, V.P., Pestova, T.V., Gajda, M., Round, A., Kong, C., Lim, M. et al. (2009) Structural insights into eRF3 and stop codon recognition by eRF1. Genes Dev., 23, 11061118.

Murashige, C.T., \& Skoog, F. (1962). A revised medium for rapid growth and bioassays with tobacco tissue cultures. Physiologia Plantarum, 15, 473-97.

D’Hont, A. N. G. E. L. I. Q. U. E., \& Glaszmann, J. C. (2001). Sugarcane genome analysis with molecular markers, a first decade of research.

[Citation: Ali, M., Rafique, F., Ali, Q., Malik, A. (2020). Genetic modification for salt and drought tolerance in plants through SODERF3. Biol. Clin. Sci. Res. J., 2020: 22 doi: https://doi.org/10.54112/bcsrj.v2020i1.22]. 
In ProcIntSoc Sugarcane Technol., 24: 556559).

Denekamp, M., \&Smeekens, S. C. (2003). Integration of wounding and osmotic stress signals determines the expression of the AtMYB102 transcription factor gene. Plant Physiology, 132(3), 1415-1423.

des Georges, A., Hashem, Y., Unbehaun, A., Grassucci, R.A., Taylor, D., Hellen, C.U., Pestova, T.V. and Frank, J. (2014) Structure of the mammalian ribosomal pre-termination complex associated with eRF1.eRF3.GDPNP. Nucleic Acids Res., 42, 3409-3418.

Dey, S., \& Corina Vlot, A. (2015). Ethylene responsive factors in the orchestration of stress responses in monocotyledonous plants. Frontiers in Plant Science, 6, 640.

Dong, J., Lai, R., Nielsen, K., Fekete, C.A., Qiu, H. and Hinnebusch, A.G. (2004) The essential ATP-binding cassette protein RLI1 functions in translation by promoting preinitiation complex assembly. J. Biol. Chem., 279, 42157-42168.

Eurwilaichitr,L., Graves,F.M., Stansfield,I. and Tuite,M.F. (1999) The C-terminus of eRF1 defines a functionally important domain for translation termination in Saccharomyces cerevisiae. Mol. Microbiol., 32, 485-496.

Grivet, L., \& Arruda, P. (2002). Sugarcane genomics: depicting the complex genome of an important tropical crop. Current opinion in plant biology, 5(2), 122-127.

Gross, T., Siepmann, A., Sturm, D., Windgassen, M., Scarcelli, J.J., Seedorf, M., Cole, C.N. and Krebber, H. (2007) The DEAD-box RNA helicase Dbp5 functions in translation termination. Science, 315, 646-649.

Gu, Y. Q., Wildermuth, M. C., Chakravarthy, S., Loh, Y. T., Yang, C., He, X., \& Martin, G. B. (2002). Tomato transcription factors Pti4, Pti5, and Pti6 activate defense responses when expressed in Arabidopsis. The Plant Cell, 14(4), 817-831.

Guo, Y. H., Yu, Y. P., Wang, D., Wu, C. A., Yang, G. D., Huang, J. G., \& Zheng, C. C. (2009). GhZFP1, a novel CCCH-type zinc finger protein from cotton, enhances salt stress tolerance and fungal disease resistance in transgenic tobacco by interacting with GZIRD21A and GZIPR5. New Phytologist, 183(1), 62-75.

Gutterson, N., \& Reuber, T. L. (2004). Regulation of disease resistance pathways by AP2/ERF transcription factors. Current opinion in plant biology, 7(4), 465-471.
Hanna-Rose, W., \& Hansen, U. (1996). Active repression mechanisms of eukaryotic transcription repressors. Trends in Genetics, 12(6), 229-234.

He, P., Warren, R. F., Zhao, T., Shan, L., Zhu, L., Tang, X., \& Zhou, J. M. (2001). Overexpression of Pti5 in tomato potentiates pathogen-induced defense gene expression and enhances disease resistance to Pseudomonas syringae pv. tomato. Molecular plant-microbe interactions, 14(12), 1453-1457.

Jackson, R.J., Hellen, C.U. and Pestova, T.V. (2012) Termination and post-termination events in eukaryotic translation. Adv. Protein Chem. Struct. Biol., 86, 45-93.

Kasuga, M., Miura, S., Shinozaki, K., \& YamaguchiShinozaki, K. (2004). A combination of the Arabidopsis DREB1A gene and stress-inducible rd29A promoter improved drought-and lowtemperature stress tolerance in tobacco by gene transfer. Plant and Cell Physiology, 45(3), 346350 .

Khoshnevis, S., Gross, T., Rotte, C., Baierlein, C., Ficner, R. and Krebber, H. (2010) The ironsulphur protein RNase L inhibitor functions in translation termination. EMBO Rep., 11, 214219.

Kispal, G., Sipos, K., Lange, H., Fekete, Z., Bedekovics, T., Janaky, T., Bassler, J., Aguilar Netz, D.J., Balk, J., Rotte, C. et al. (2005) Biogenesis of cytosolic ribosomes requires the essential iron-sulphur protein Rli1p and mitochondria. EMBO J., 24, 589-598.

Kloepper JW, Ryu CM, Zhang S. (2004). Induced systemic resistance and promotion of plant growth by Bacillus spp. Phytopathology., 94:1259-66

Liu, Q., Kasuga, M., Sakuma, Y., Abe, H., Miura, S., Yamaguchi-Shinozaki, K., \& Shinozaki, K. (1998). Two transcription factors, DREB1 and DREB2, with an EREBP/AP2 DNA binding domain separate two cellular signal transduction pathways in drought-and lowtemperature-responsive gene expression, respectively, in Arabidopsis. The Plant Cell, 10(8), 1391-1406.

Trujillo, L.E., M. Sotolongo, C. Menendez, M. E. Ochogavia, Y.Coll, I. Hernandez, O. BorrasHidalgo, B.P.H.J. Thomma, P. Vera, L. Hernandez. (2008). SodERF3, a novel Factor enhances salt tolerance and drought when over expressed in tobacco plants. Plant and Cell Physiology. 49(4), 512-525

Menke, F. L., Champion, A., Kijne, J. W., \& Memelink, J. (1999). A novel jasmonate-and

[Citation: Ali, M., Rafique, F., Ali, Q., Malik, A. (2020). Genetic modification for salt and drought tolerance in plants through SODERF3. Biol. Clin. Sci. Res. J., 2020: 22 doi: https://doi.org/10.54112/bcsrj.v2020i1.22]. 
elicitor-responsive element in the periwinkle secondary metabolite biosynthetic gene Str interacts with a jasmonate-and elicitor-inducible AP2-domain transcription factor, ORCA2. The EMBO Journal, 18(16), 4455-4463.

Merkulova, T.I., Frolova,L.Y., Lazar,M., Camonis,J. and Kisselev,L.L. (1999) C-terminal domains of human translation termination factors eRF1 and eRF3 mediate their in vivo interaction. FEBS Lett., 443, 41-47.

Mikhailova, T., Shuvalova, E., Ivanov, A., Susorov, D., Shuvalov, A., Kolosov, P.M. and Alkalaeva, E. (2017) RNA helicase DDX19 stabilizes ribosomal elongation and termination complexes. Nucleic Acids Res., 45, 1307-1318.

Mith S, Read D. Mycorrhizal symbiosis. Cambridge, UK: Academic press, 2008.

Neumann, B., Wu, H., Hackmann, A. and Krebber, H. (2016) Nuclear export of Pre-Ribosomal subunits requires Dbp5, but not as an RNAHelicase as for mRNA export. PLoS One, 11, e0149571.

Noble, K.N., Tran, E.J., Alcazar-Roman, A.R., Hodge, C.A., Cole, C.N. and Wente, S.R. (2011) The Dbp5 cycle at the nuclear pore complex during mRNA export II: nucleotide cycling and mRNP remodeling by Dbp5 are controlled by Nup159 and Gle1. Genes Dev., 25, 1065-1077.

Orlowska E, Basile A, Kandzia I, Llorente B, Kirk HG, Cvitanich C. (2012). Revealing the importance of meristems and roots for the development of hypersensitive responses and full foliar resistance to Phytophthora infestans in the resistant potato cultivar Sarpo Mira. J Exp Bot., 63:4765-79

Pisarev, A.V., Skabkin, M.A., Pisareva, V.P., Skabkina, O.V., Rakotondrafara, A.M., Hentze, M.W., Hellen, C.U. and Pestova, T.V. (2010) The role of ABCE1 in eukaryotic posttermination ribosomal recycling. Mol. Cell, 37, 196-210.

Preis, A., Heuer, A., Barrio-Garcia, C., Hauser, A., Eyler, D.E., Berninghausen, O., Green, R., Becker, T. and Beckmann, R. (2014) Cryoelectron microscopic structures of eukaryotic translation termination complexes containing eRF1-eRF3 or eRF1-ABCE1. Cell Rep., 8: 59-65.

Puranik, S., Sahu, P. P., Srivastava, P. S., \& Prasad, M. (2012). NAC proteins: regulation and role in stress tolerance. Trends in plant science, 17(6), 369-381.

Quan, R., Hu, S., Zhang, Z., Zhang, H., Zhang, Z., \& Huang, R. (2010). Overexpression of an ERF transcription factor TSRF1 improves rice drought tolerance. Plant Biotechnology Journal, 8(4), 476-488.

Salas-Marco, J. and Bedwell, D.M. (2004) GTP hydrolysis by eRF3 facilitates stop codon decoding during eukaryotic translation termination. Mol. Cell. Biol., 24, 7769-7778.

Shoemaker, C.J. and Green, R. (2011) Kinetic analysis reveals the ordered coupling of translation termination and ribosome recycling in yeast. Proc. Natl. Acad. Sci. USA, 108, E1392-E1398.

Shoemaker,C.J., Eyler,D.E. and Green,R. (2010) Dom34:Hbs1 promotes subunit dissociation and peptidyl-tRNA drop-off to initiate no-go decay. Science, 330, 369-372.

Strunk,B.S., Novak,M.N., Young,C.L. and Karbstein,K. (2012) A translation-like cycle is a quality control checkpoint for maturing $40 \mathrm{~S}$ ribosome subunits. Cell, 150, 111-121.

Taylor, D., Unbehaun, A., Li, W., Das, S., Lei, J., Liao, H.Y., Grassucci, R.A., Pestova, T.V. and Frank, J. (2012) Cryo-EM structure of the mammalian eukaryotic release factor eRF1eRF3-associated termination complex. Proc. Natl. Acad. Sci. USA, 109, 18413-18418.

Tieg, B. and Krebber, H. (2013). Dbp5 - From nuclear export to translation. Biochim. Biophys. Acta, 1829, 791-798.

Trujillo, L. E., Sotolongo, M., Menendez, C., Ochogavia, M. E., Coll, Y., Hernandez, I., ...\& Hernandez, L. (2008). SodERF3, a novel sugarcane ethylene responsive factor (ERF), enhances salt and drought tolerance when overexpressed in tobacco plants. Plant and Cell Physiology, 49(4), 512-525.

Yarunin, A., Panse, V.G., Petfalski, E., Dez, C., Tollervey, D. and Hurt, E.C. (2005) Functional link between ribosome formation and biogenesis of iron-sulfur proteins. EMBO J., 24, 580-588.

Zuo, K. J., Qin, J., Zhao, J. Y., Ling, H., Zhang, L. D., Cao, Y. F., \& Tang, K. X. (2007). Overexpression GbERF2 transcription factor in tobacco enhances brown spots disease resistance by activating expression of downstream genes. Gene, 391(1-2), 80-90.

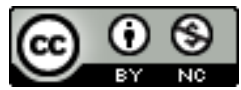

Open Access This article is licensed under a Creative Commons Attribution 4.0 International License, which permits use, sharing, adaptation, distribution and reproduction in any medium or format, as long as you give appropriate credit to the original author(s)

[Citation: Ali, M., Rafique, F., Ali, Q., Malik, A. (2020). Genetic modification for salt and drought tolerance in plants through SODERF3. Biol. Clin. Sci. Res. J., 2020: 22 doi: https://doi.org/10.54112/bcsrj.v2020i1.22]. 
and the source, provide a link to the Creative Commons licence, and indicate if changes were made. The images or other third party material in this article are included in the article's Creative Commons licence, unless indicated otherwise in a credit line to the material. If material is not included in the article's Creative Commons licence and your intended use is not permitted by statutory regulation or exceeds the permitted use, you will need to obtain permission directly from the copyright holder. To view a copy of this licence, visit http://creativecommons.org/licen ses/by/4.0/.

(C) The Author(s) 2021

[Citation: Ali, M., Rafique, F., Ali, Q., Malik, A. (2020). Genetic modification for salt and drought tolerance in plants through SODERF3. Biol. Clin. Sci. Res. J., 2020: 22 doi: https://doi.org/10.54112/bcsrj.v2020i1.22]. 